\title{
Balıkesir ilinde tarımsal danışmanlık hizmetinin etkisinin değerlendirilmesi
}

\section{Impact Assessment of Agricultural Consultancy Service in Balıkesir Region}

\author{
Hakan IMAMOĞLU ${ }^{1}$ iD, Ferit ÇOBANOĞLU ${ }^{2 *}$ iD \\ ${ }^{1}$ Gıda, Tarım ve Hayvancılık Bakanlığı, Balıkesir ì Müdürlüğü, Balıkesir, Türkiye \\ ${ }^{2}$ Adnan Menderes Üniversitesi, Ziraat Fakültesi, Tarım Ekonomisi Bölümü, Aydın, Türkiye
}

\section{To cite this article:}

İmamoğlu, H., Çobanoğlu, F., 2018. Balıkesir ilinde tarımsal danışmanlık hizmetinin etkisinin değerlendirilmesi. Harran Tarim ve Gida Bilimleri Dergisi, 22(2): 263-274

Address for Correspondence: Ferit ÇOBANOĞLU e-mail:

ferit.cobanoglu@adu.edu.tr

Received Date:

30.06.2017

Accepted Date:

08.03.2018

(c) Copyright 2018 by Harran University Faculty of Agriculture. Available on-line at www.dergipark.gov.tr/harranziraat öz

Bu çalışmada, Balıkesir ilinde, Tarımsal Danışmanlık Hizmeti (TDH)’nden yararlanan ve yararlanmayan işletmeler, karşıt durum etki değerleme yöntemi kullanılarak analiz yapılmıştır. Yörede, gayeli olarak belirlenmiş olan 143 işletmeyle yüz yüze anket uygulaması gerçekleştirilmiştir. 72 işletme TDH'nden yararlanan, 71 işletme ise TDH'nden yararlanmayan işletmelerden seçilmiştir. Anket çalışmaları 2014-2015 yıllarında yapılmıştır. Başlıca üretici ve tarımsal işletme karakteristiklerinin (yaş, eğitim, deneyim, hanedeki birey sayısı, hanedeki tarımda çalışan kişi sayısı) belirlenmesinde; tanımlayıcı istatistikler (aritmetik ortalama, standart sapma vb.) kullanılmıştır. Etki değerleme analizinde de; TDH'nin, tarımsal işletmelerde elde edilen yıllık ortalama toplam tarımsal gelir ve işletme varlıklarının ekonomik büyüklüğü üzerine etkileri analiz edilmiştir. Bunun için, ortalama müdahale etkisi (Average Treatment Effect: ATE) değerleri incelendiğinde; tüm işletmelerin TDH'nden yararlanması durumunda, işletme başına düşen yıllık ortalama toplam tarımsal gelir, işletmelerin hiçbirinin TDH'nden yararlanmaması durumuna göre elde edilecek gelirden 4,986 TL daha fazla olacağı belirlenmiştir. TDH'nden (müdahaleden) yararlanmış işletmelerde, TDH'nin etkisini ortaya koyan (Average Treatment Effect on Treated: ATET) analiz sonuçları değerlendirildiğinde ise; TDH'nden yararlanan tüm işletmeler için, bu işletmelerin elde ettikleri yıllık toplam tarımsal gelir, bu işletmelerin (TDH'nden yararlanan) TDH'nden yararlanmaması durumunda elde edecekleri gelirden 4,972 TL daha fazla olduğu belirlenmiştir. Yine, ATE sonucuna göre; tüm işletmelerin TDH'nden yararlanması durumunda, işletme varlıklarının ekonomik büyüklüğü, işletmelerin hiçbirinin TDH'nden yararlanmaması durumunda oluşacak büyüklükten 0.44 kategori (derece) daha yüksek olacağı belirlenmiştir. ATET sonucuna göre ise, $T D H^{\prime}$ nden yararlanan tüm işletmeler için, bu işletmelerin elde ettikleri işletme varlıklarının ekonomik büyüklüğü, söz konusu işletmelerin, TDH'nden yararlanmaması durumunda elde edecekleri ekonomik büyüklükten 0.31 kategori daha fazla olacağı belirlenmiştir.

Anahtar Kelimeler: Tarımsal danışmanlık, Karşıt durum, Etki değerleme, Ortalama müdahale etkisi, Müdahale edilmiş durumdaki ortalama müdahale etkisi

\section{ABSTRACT}

In this study, the farm groups both could be benefit from Agricultural Consultancy Service (AGS) and could not be benefit from AGS operated in Balıkesir region are analyzed using by the method of counterfactual impact assessment. In this region, the survey study is carried out with 143 farms selected by purpose in the shape of face to face meeting. 72 farms from those that could benefit from AGS and also 71 farms from that could not benefit from AGS are selected. The survey studies are performed in 20142015 years. In defining essential producer and agricultural farm characteristics (age, education, experience, the number of members in household, the number of person 
worked in agriculture), descriptive statistics (mean, standard deviation etc.) are used. According to the impact assessment analysis performed, average treatment effect (ATE) investigated could declare that total average annual agricultural incomes per farm would be more than 4,986 TL if all the farms could be benefit from AGS compared with the circumstance that none of the farms could be benefit from AGS. In evaluation analysis of average treatment effect on the treated (ATET) identified AGS treatment in the farms that could be benefit from AGS; total average annual agricultural incomes per farm would be more than 4,972 TL if the same farms could not be benefit from AGS. ATE results investigated could declare that economic size of the farm assets per farm would be more than 0.44 category (level) if all the farms could be benefit from AGS compared with the circumstance that none of the farms could be benefit from AGS. According to ATET identified AGS treatment in the farms that could be benefit from AGS; economic size of the farm assets per farm would be more than 0.31 category (level) if the same farms could not be benefit from AGS.

Key Words: Agricultural consultancy, Counterfactual, Impact assessment, Average treatment effect, Average treatment effect on treated

\section{Giriş}

Tarımsal danışmanlık kavramına girmeden önce, bu kavram içerisinde önemli bir yeri oluşturan tarımsal yayım kavramının tanımlanmasının oldukça önemli olduğu düşünülmektedir. Tarımsal yayım; tarımsal üretimi artırmak ve tarım politikalarının şeffaflığını sağlamak amacı ile modern ve bilimsel çalışma teknolojilerinin araştırma ve sonuçlarını, üreticinin kullanabileceği formlara uyarlamak şeklinde tanımlanabilmektedir (Çınar, 2009). Ayrıca yine tarımsal yayım, tarım alanında ortaya çıkan yeni bilgi, teknik ve araçlar konusunda çiftçilerin eğitilmesi, bilgilendirilmesi, onlara bu yeni bilgi teknik ve araçların eğitimsel bir süreç içerisinde benimsetilmesi çalışmaları olarak da açıklanabilmektedir. Böylece onların ekonomik, sosyal ve kültürel açıdan kalkınmalarına yardımcı olmak şeklinde bir diğer tanımlama yapılması da mümkün olabilmektedir (Yavuz, 2000).

Tarımsal yayım geniş olarak düşünüldüğünde, tarımsal ve kırsal kalkınma sürecinde birçok amacı gerçekleştirebilir. Tarımsal yayımın temel amacı, kırsal alanda yaşayan insanların yaşam düzeylerini yükseltmelerine yardımcı olmaktır. Yayım politikasının amaçları genellikle her ülkenin tarım politikası ve kalkınma amaçlarıyla doğrudan ilişkilidir. Bu amaçlar koşullara göre değişebilmektedir. Örneğin, Türkiye'de yayım politikasının genel amacı, tarımsal ürünlerin üretim ve verimliliğini arttırmak iken, bazı ülkelerde amaç gıda güvenliğini sağlamak veya sürdürülebilir üretimi gerçekleştirmek olabilmektedir (Çukur, 2007).
Dünyada tarımsal yayım hizmetlerinin sunumu devlet, tarımsal örgütler, özel sektör, meslek kuruluşları ya da bu kuruluşların birleşmesi halinde gerçekleştirilebilmektedir. Ancak az gelişmiş ve gelişmekte olan ülkelerde, tarımsal yayım hizmetinin sunumu, genellikle devlet tarafından yürütülmektedir (Tunalıoğlu ve Çınar, 2013).

Kızılaslan ve Erdemir (2013) Tokat ilinde yapmış oldukları bir araştırmada, bölgede çalışan tarım danışmanlarının tarımsal yayım ve danışmanlık sistemine bakışlarını ortaya koyarak, mesleki gelişim kapasitelerini belirleyip, bazı çözüm önerileri geliştirmeyi amaçlamışlardır. Bu amaca yönelik olarak, 26 tarım danışmanı belirlenerek anket uygulanmıştır. Sonuç olarak bölgede tarım danışmanlığının istenilen seviyede olmadığı, danışmanların istekli ve çaba içerisinde oldukları, çiftçiler ve yönetmelikle ilgili sorunlar olduğu tespit edilmiş olup, ayrıca uygulanmakta olan, danışmandan yardım alan çiftçilere yönelik devlet desteği sistemi yerleştirilene kadar devam ettirilmesi gerektiği vurgulanmıştır.

Tarım danışmanı, "Sivil toplum örgütlerinde, ziraat odalarında istihdam edilen ve Yönetmelikte belirtilen hükümlere göre sertifikalandırılmış kişileri", tarımsal danışmanlık hizmetleri "Sivil toplum örgütleri ve ziraat odalarınca tarımsal işletmelerin tarımsal bilgi, teknik ve yöntemler konusundaki ihtiyaçlarının zamanında ve yeterli düzeyde karşılanmasına yönelik olarak ücret karşılığında yürütülen hizmetleri", tarımsal yayım ve danışmanlık desteği (TYDD) ise "Tarımsal danışmanlık hizmeti sunan kuruluşlara sunduğu tarımsal danışmanlık hizmeti için ödenen desteği" 
olarak ifade edilmektedir (TCRG, 2016).

Tarımsal yayım ve tarımsal danışmanlık desteği ve uygulamaları, Türkiye'de belirli bir gelişim göstermekle birlikte, halen söz konusu gelişim ve değişimin, dinamik olarak devam etmekte olduğu ifade edilebilir. 2016 yılında, Tarımsal Yayım ve Danışmanlık Hizmetlerinin Düzenlenmesine Dair Yönetmeliğine bağlı olarak "Tarımsal Yayım ve Danışmanlık Hizmetleri Uygulama Esasları" ile "Tarımsal Yayım ve Danışmanlık Sınavı Uygulama Esasları" yeniden düzenlenerek yürürlüğe girmiştir. Yönetmeliğin amacı; tarımsal işletmelerin tarımsal bilgi, teknik ve yöntemler konusundaki ihtiyaçlarının zamanında ve yeterli düzeyde karşılanmasına yönelik olarak Kamu ve Kamu Dışı Tarımsal Yayım Danışmanlık Hizmetleri ile ilgili kural, usul ve yöntemleri belirlemektir. Yönetmeliğin uygulamaya konulduğu 2006 yılından başlamak üzere 2016 yılı sonuna kadar 3,323 kişiye Tarım Yayımcısı Sertifikası, 14,058 kişiye Tarım Danışmanı Sertifikası verilmiştir (GTHB, 2016). Tarımsal Yayım ve Danışmanlık Hizmetlerini sunmak üzere yönetmeliğin uygulamaya konulduğu 2006 yılından itibaren üretici örgütü, ziraat odası, dernek, 159 şirket ve serbest danışman olmak üzere toplam 1,525 kişi / kuruluşa Tarımsal Danışmanlık Yetki Belgesi verilmiştir. Ülkemiz genelinde Tarımsal Danışmanlık Hizmeti (TDH) sunmak üzere 2016 yılsonu itibariyle yetki verilen 753 Tarım Danışmanı toplam 45,786 çiftçiye TDH vermektedir. Ayrıca yapılan eğitim ve yayım çalışmalarının desteklenmesi amacıyla, Tarımsal Yayım ve Danışmanlık Hizmetlerine Destekleme Ödemesi kapsamında destekleme ödemelerinin başlatıldığı 2009 yılından itibaren 2016 yılı sonu itibariyle toplam 576,494 tarımsal işletme için 307,739,325 TL destekleme ödemesi yapılmıştır. Bakanlar Kurulu Kararı gereği, tarımsal danışmanlık şirketleri, serbest tarım danışmanları ve dernekler, tarımsal yayım ve danışmanlık desteklemesi (TYDD) ödemesi kapsamı dışına çıkarılmış olup, 2016 yılında sadece ziraat odaları ve üretici örgütlerine, TYDD ödemesinden faydalanma imkanı tanınmıştır (GTHB, 2016).

Gıda, Tarım ve Hayvancılık Bakanlığı (GTHB) taşra teşkilatında yer alan il ve ilçe müdürlüklerinin daha etkin ve verimli çalışma yürütebilmesi amacıyla "Tarımsal İşletme Danışmanı (TID)" olarak ifade edilen "işletme bazlı" yeni bir çalışma modeline geçilmesi kararlaştırılmıştır. İşletme bazlı yeni modelde çalışacak personel; eğitim ve yayım, hayvan sağlığı ve üretimi, bitki sağlığı ve üretimi, desteklemeler ve kontrolü, istatistik ve veri güncelleme görevlerinin yanı sıra intiyaç halinde il veya ilçe müdürlükleri tarafından verilecek diğer görevleri de (gıda denetimi, mera, toplulaştırma hizmetleri vb.) yürüteceklerdir. TiD’ları, işletme ziyaretlerine başlatılmıştır. Bu kapsamda 2016 yılında 300,913 tarımsal (bitkisel) işletme ve 286,336 tarımsal (hayvansal) işletme ziyaret edilmiştir. TiD Uygulama Esasları hazırlık çalışmaları yapılmıştır (GTHB, 2016).

Çalışmanın yapıldığı Balıkesir ilinde, Gıda, Tarım ve Hayvancılık iı Müdürlüğü, Koordinasyon ve Tarımsal Veriler Şube Müdürlüğü kayıtlarına göre; 2013 yılında 5 kuruluşa, 252 tarımsal işletmeye danışmanlık hizmeti verilmesi ile 150,800 TL destekleme ödemesi yapılmıştır. 2014 yılında ise 11 tarımsal kuruluşa, 1,065 tarımsal işletmeye danışmanlık hizmeti verilmesinden dolayı 639.000 TL destekle ödemesi yapılmıştır. 2013 ile 2014 yılları karşılaştırıldığında, 4 katın üzerinde bir artışın olduğu görülmektedir (Çizelge 1) (Balıkesir GTHB ì Müdürlüğü, 2015).

$\mathrm{Bu}$ çalışmanın ana amacı, Balıkesir ilinde, TDH'nden yararlanan ve yararlanmayan işletmeler dikkate alınarak, karşıt durum yöntemi ile etki değerleme analizinin, diğer bir ifade ile müdahale etkisinin ortaya konulmasıdır.

\section{Materyal ve Metot}

\section{Materyal}

Anket çalışması yapılan TDH'nden yararlanan 72 işletme, 2015 yılında Balıkesir ilinde TDH'nden yararlanan 1,385 tarımsal işletmeden seçilmiş olup, anket çalışması yapılan, TDH'nden yararlanmayan 71 işletme ise, Çiftçi Kayıt Sistemine (ÇKS) kayıtlı olan, ancak tarımsal danışmanlık hizmetinden yararlanmayan işletmelerden seçilmiştir (Çizelge2). 
Çizelge 1. Yıllara göre Balıkesir iline verilen Tarımsal Yayım Danışmanlık Desteği

Table 1. Supports for Agricultural Extension and Consultancy Endowed to Balıkesir city by years

\begin{tabular}{|c|c|c|c|c|}
\hline $\begin{array}{l}\text { Yıllar } \\
\text { Years }\end{array}$ & $\begin{array}{c}\text { Tarımsal işletme sayısı } \\
\text { (adet) }\end{array}$ & $\begin{array}{c}\text { Toplam destekleme } \\
\text { odemesi (TL) } \\
\text { Total support payment } \\
(\mathrm{TL})\end{array}$ & $\begin{array}{c}\text { Tarımsal işletme sayısındaki artış } \\
\text { oranı (\%) The rate of increase in } \\
\text { the number of farms (\%) }\end{array}$ & $\begin{array}{c}\text { Işletme başına ödeme } \\
\text { miktarı (TL) Support } \\
\text { amount per farm (TL) }\end{array}$ \\
\hline 2009 & 0 & 0 & - & 225 \\
\hline 2010 & 91 & 45,500 & - & 500 \\
\hline 2011 & 108 & 54,000 & 36.68 & 500 \\
\hline 2012 & 498 & 298,800 & 49.40 & 600 \\
\hline 2013 & 252 & 150,800 & 322.62 & 600 \\
\hline 2014 & 1,065 & 639,000 & 30.05 & 600 \\
\hline 2015 & 1,385 & 857,000 & & \\
\hline
\end{tabular}

Kaynak: Balıkesir GTHB il Müdürlüğü verileri, 2015.

Reference: Balıkesir City Directorate of MFAL's data, 2015.

Çizelge 2. Balıkesir ilinde ÇKS'ne kayıtlı olan ve TDH'nden yararlanan işletmeler

Table 2. The farms registered to Farmer Register System (FRS) and benefited from Agricultural Consultancy Services (ACS) in Balıkesir city

\begin{tabular}{|c|c|c|c|c|c|}
\hline & \multirow{2}{*}{$\begin{array}{l}\text { ÇKS'ne kayıtlı } \\
\text { üretici sayısı } \\
\text { (adet) } \\
\text { The number of } \\
\text { producers } \\
\text { registered to FRS } \\
\text { (n) }\end{array}$} & \multirow{2}{*}{$\begin{array}{l}\text { TDH'nden } \\
\text { yararlanan } \\
\text { işletme sayısı } \\
\text { (adet) The } \\
\text { number of } \\
\text { farms benefited } \\
\text { from ACS }(n)\end{array}$} & \multicolumn{2}{|c|}{$\begin{array}{l}\text { Anket yapılan toplam işletme sayısı (adet) } \\
\text { The number of total farms interviewed }(n)\end{array}$} & \multirow{2}{*}{$\begin{array}{l}\text { Anket yapılan } \\
\text { toplam işletme } \\
\text { sayısı (adet) } \\
\text { The number of } \\
\text { total farms } \\
\text { interviewed (n) }\end{array}$} \\
\hline & & & $\begin{array}{l}\text { TDH'nden yararlanan } \\
\text { işletme sayısı (adet) } \\
\text { The number of farms } \\
\text { benefited from ACS ( } n \text { ) }\end{array}$ & $\begin{array}{c}\text { TDH'nden } \\
\text { yararlanmayan işletme } \\
\text { sayısı (adet) The number } \\
\text { of farms couldn't } \\
\text { benefited from ACS }(n)\end{array}$ & \\
\hline Balıkesir & 44,822 & 1,385 & 72 & 71 & 143 \\
\hline
\end{tabular}

Kaynak: Balıkesir GTHB il Müdürlüğü verileri, 2015.

Reference: Balıkesir City Directorate of MFAL's data, 2015.

Metot

\section{Verilerin Toplanmasında Kullanılan Yaklaşım}

Pratik nedenlerle, olasılık örnekleme yaklaşımının kullanımı mümkün olmadığı durumlarda, temsil yeteneğinin belki de bir dereceye kadar sağlanmasıyla, olasılığa dayalı olmayan örneklemeye başvurulabilir (Özen ve Gül, 2007). Olasılığa dayalı olmayan örneklemelerde, yansızlık kuralına uymak yerine, belli özellikleri taşıması koşulu aranır (Monette et al., 1990; Balcı, 2011). Olasılığa dayalı olmayan örneklemeler içerisinde bulunan amaçlı örneklemeye yargısal örnekleme de denir. Araştırmacılar için evrenin genelini temsil edecek bir örneklem seçmek temel amaçtır. Fakat bazı durumlarda, koşulların kontrol altına alındığı problemlerde evrenden yüzeysel olarak farklı olan, araştırma için önemli olan özellikler bakımından ortalama düzeyde bunlara sahip olunmasına dikkat edilerek bir örneklem seçilmesini araştırmacı uygun görebilir. Bu tip örnekleme yargısal (judgmental) örnekleme olarak da adlandırılır. Araştırmacılar kendi yargılarını veya önceden edinmiş oldukları bilgilerini kullanarak örneklem seçerler, yani araştırmanın amacına hizmet edecek kişileri seçmeyi tercih ederler (Monette et al., 1990). Bu sebeplerle çalışmada, anket yapılacak üreticilerin belirlenmesinde, olasılığa dayalı olmayan örnekleme tekniklerinden amaçlı örnekleme (purposive sampling) teknikleri içerisinde bulunan ölçüt örnekleme yöntemi kullanılmıştır. Ölçüt örnekleme yönteminde temel anlayış, önceden belirlenmiş bir dizi ölçütü karşılayan bütün durumların çalışılmasıdır (Şimşek ve Yıldırım, 2013; Kahramanoğlu ve ark., 2015). Balıkesir ilinde, tarımsal danışmanlık hizmetinin, tarımsal üretim üzerine etkilerinin belirlenmesi amacıyla yapılan çalışma için, bölgede gayeli olarak belirlenmiş olan 143 işletmeyle yüz yüze anket uygulaması gerçekleştirilmiştir. 72 adet işletme TDH'nden yararlanan işletmelerden, 71 işletme ise TDH'nden yararlanmayan, ancak TDH'nden yararlanan işletmelerle yaklaşık olarak benzer 
işletme karakteristiklerine (arazi varlığı, üretim deseni, makine-ekipman varlığı vb.) sahip olanlardan seçilmiştir. Anket çalışmaları 20142015 yıllarında yapılmıştır.

\section{Verilerin Analizinde Kullanılan Yöntemler}

Başlıca üretici ve tarımsal işletme karakteristiklerinin (yaş, eğitim, deneyim, hanedeki birey sayısı, hanedeki tarımda çalışan kişi sayısı) belirlenmesinde, tanımlayıcı istatistikler (aritmetik ortalama, standart sapma vb.) kullanılmıştır. Etki değerleme analizinde de; TDH'nin, tarımsal işletmelerde elde edilen yıllık ortalama toplam tarımsal gelir ve işletme varlıklarının ekonomik büyüklüğü üzerine etkileri analiz edilmiştir.

\section{Tarımsal Danışmanlık Hizmetinden Yararlanmanın} Etkisinin Belirlenmesine Yönelik Analitik Çerçeve ve Metodoloji

\section{Tarımsal Danışmanlık Hizmeti (TDH)'nden} Yararlanma Kararı

Kassie et al. (2011), Blackman and Naranjo (2012) ve Pan (2014)' a dayalı olarak bir üreticinin, TDH'nden yaralanmasının altını çizen analitik çerçeveyi yönlendiren ekonomik rasyonel, algılanan fayda maksimizasyonudur. Üreticilerin TDH'nden yararlanıp-yararlanmama kararı, bu hizmetten yararlanma ile elde edilecek üreticilerin beklemiş olduğu faydaya bağlı olmaktadır. TDH'nden işletmenin yararlanması sadece, yararlanmanın beklenen faydasının $\left(U_{p}\right)$, yararlanmama durumunda oluşacak faydadan $\left(U_{n}\right)$ daha büyük olmasında, örneğin $U_{p}-U_{n}>0$ durumunda gerçekleşecektir. Yararlanma olması ya da olmaması durumunda oluşacak faydalar arasındaki farklılık gizli bir $D_{i}^{*}$ değişkeni ile ifade edilebilir. Öyle $\mathrm{ki}, D_{i}^{*}>0$ olması, yararlanma durumunda oluşacak faydanın, yararlanmama durumunda oluşacak faydayı aştığını işaret etmektedir. Bu sebeple, ${ }^{D_{i}^{*}}$ gözlenmemekte fakat aşağıdaki bir gizli değişken modelinde, $Z_{i}$ olarak belirtilen gözlenen ve karakteristikler ve özelliklerin bir fonksiyonu olarak açıklanabilmektedir:

$$
\begin{aligned}
& D_{i}^{*}=\beta Z_{i}+\varepsilon_{i} \\
& D_{i}=\left\{\begin{array}{l}
1, \text { eger } \mathrm{D}_{\mathrm{i}}^{*}>0 \\
0, \text { diger durum }
\end{array}\right.
\end{aligned}
$$

burada, $D_{i}$ ikili bir indikatör değişkeni olup, eğer bir işletme, TDH'nden yararlanıyorsa 1 , diğer durumda sıfırı (0) işaret etmekte; $b_{i}$ tahmin edilecek bir parametreler vektörü; $Z_{i}$ bir açıklayıcı (bağımsız) değişkenler vektörü olup, $\varepsilon_{i}$ ise normal olarak dağıldığı varsayılan bir hata terimidir.

Gözlenebilir karakteristiklere dayalı olarak bir işletme tarafından, bir TDH'nden yararlanma olasılığı, ikili bir probit ya da logit modeli kullanılarak tahmin edilebilmektedir:

$$
\operatorname{Pr}\left(D_{i}=1\right)=\operatorname{Pr}\left(D_{i}^{*}>0\right)=\operatorname{Pr}\left(\varepsilon_{i}>-\beta Z_{i}\right)=1-F\left(-\beta Z_{i}\right)
$$

burada; $F$, çoğu kez, probit modelde normal dağıldığı varsayılan ya da logit modelde ekstrem değer dağılan $\varepsilon_{i}$ için kümülatif dağılım fonksiyonudur. Ekstrem değer dağılım hatası, bunun lojistik dağılım fonksiyonunu vermektedir.

Bir işletmenin, TDH'nden yararlanma ya da yaralanmama kararı, üretici karakteristikleri ile birlikte işletme özelliklerine de bağlıdır. Bu sebeple, tarımsal işletmelerin rastgele belirlenmesinden ziyade, herbir işletmenin kendisinin belirlenmesinin önemli olduğu düşünülmektedir.

Işletmelerin TDH'nden Yararlanması ile işsletmede Elde Edilen Yıllık Toplam Tarımsal Gelir ve Işletme Varlıklarının Ekonomik Büyüklüğ̈̈ Üzerine Etkisi

İşletmelerin TDH'nden yararlanmasının, işletmede elde edilen yıllık toplam tarımsal gelir ve işletme varlıklarının ekonomik büyüklüğünü oluşturmaya ve/veya geliştirmeye yönelik üretici davranışının etkisinin belirlenmesine yönelik ortak yaklaşım şu şekildedir. Üreticinin TDH'nden yararlanma durumu bir (1) kukla (dummy) değişkeni ile belirtilirken, diğer durumu sıfır (0) ifade etmektedir. Sonra, klasik en küçük kareler (EKK) regresyonu uygulanır. Bu durum, aşağıdaki 
gibi ifade edilebilir (Pan, 2014):

$\operatorname{Davranis}_{i}=a X_{i}+\tau D_{i}+u_{i}$

burada; Davranis $s_{i}$ ifadesi, i üreticisinin yıllık toplam tarımsal gelir ve işletme varlıklarının ekonomik büyüklüğünü oluşturmaya ve/veya geliştirmeye yönelik davranışlarını sunmaktadır. $X_{i}$ vektörü, yaş, eğitim, deneyim, hanede çalışan tarımsal kişi sayısı, kooperatife üyelik ve karma işletme özelliği gibi, işletme ve üretici düzeyindeki karakteristikleri; $\quad D_{i} \quad$ kukla değişkeni, $\quad D_{i}=1$ TDH'nden yararlanmayı ve $D_{i}=0$ ise diğer durumu ifade etmektedir. Modeldeki $\tau$ katsayısı, üreticisinin yıllık toplam tarımsal gelir ve işletme varlıklarının ekonomik büyüklüğünü oluşturmaya ve/veya geliştirmeye yönelik davranışları üzerinde TDH'nden yararlanmanın etkisini ortaya koymaktadır. Ancak bu yaklaşım, muhtemelen yanlı tahminler oluşturmaktadır. Çünkü bu durum, TDH'nden yararlanmanın, dışsal olarak belirlendiğini varsaymaktadır. Buna karşın, bu durum potansiyel olarak içseldir. TDH'nden yararlanma tesadüfi olmayıp, yıllık toplam tarımsal gelir ve işletme varlıklarının ekonomik büyüklüğünü oluşturmaya ve/veya geliştirmeye yönelik üretici davranışları ile ilişkili olabilen, gözlenemeyen tarımsal işletme ve üretici karakteristikleri (örneğin; yönetimsel yetenek, motivasyon vb.) ile güçlü bir korelasyona sahiptir. $\mathrm{Bu}$ durum, stratejik program yerleştirmesi ya da TDH'nden yararlanma için üreticinin kendi kendisini seçmesinden olabilir. Eğer gözlenemeyen faktörler, Denklem (1)'de TDH'nde yararlanma denklemi hata terimi olan $\varepsilon_{i}$ ile Denklem (4)'deki yıllık toplam tarımsal gelir ve işletme varlıklarının ekonomik büyüklüğünü oluşturmaya ve/veya geliştirmeye yönelik davranışların hata terimi olan $u_{i}$ hata teriminin her ikisini etkilerse, iki hata terimi arasında korelasyon oluşması sonucu seçim yanlılığı konusu oluşmaktadır. Bu sebeple, Denklem (4)'ün en küçük kareler yöntemi ile tahmin edilmesi, yanlı tahminlere yol açacaktır.

Araştırıcılar, seçim yanlılığını önlemek için farklı yöntemler önermişlerdir (Gitonga et al., 2013): (1) TDH'nden yararlananların, kontrol ya da müdahale gruplarına tesadüfi olarak atanabildiği deneysel bir çalışma söz konusudur. Fakat bu durum, olay sonrası (ex-post) çalışmalar için olası değildir. (2) Asıl kısıtlama olarak, ampirik çalışmalarda oldukça güç bir görev olan, normalde müdahale durumunu belirleyip, çıktı değişkenini belirlemeyen, geçerli bir enstrümana gereksinim duyan araçsal değişkenler (IV) yaklaşımı (Ali and Abdulai, 2010). Buna ek olarak, IV prosedürü, müdahale değişkeninin, çıktı değişkeni üzerinde sadece paralel bir değişikliğe (kesen etkisi) yol açması, TDH'nden yararlanma ve diğer ortak faktörler arasındaki etkileşimlerin mevcut olmadığını ortaya koymaktadır. (3) Heckman'ın iki-aşamalı yöntemi; ancak bu iki-aşama yöntemi, gözlenemeyen değişkenlerin normal olarak dağıldığı kısıtlayıcı varsayıma bağı olmaktadır (Heckman et al., 1997). (4) Bir müdahalenin öncesi ve sonrasını ve müdahale edilen ve edilmeyen gruplar arasındaki etkiyi inceleyen bir farkın farkı yaklaşımı; bu nedenle, söz konusu yöntem, panel verilere (longitudinal data) dayalı çalışmalar ile kısıtlanmıştır. (5) Yukarıda bahsedilen yöntemlere benzemeyen bir eğilim skoru-eşleştirme yöntemi (propensity scorematching method), çıktı ve çıktı tahmincileri arasındaki ilişkileri tahmin eden fonksiyonel form hakkında hiçbir varsayıma gerek duymaz. Bu sebeple, geçerli araçsal değişkenlerin bulunması güçlüğünün önlenebilmesi ve zamanın bir noktasında toplanan çapraz veri kullanılabilmektedir (Dehejia and Wahba, 2002; Smith and Todd, 2005).

Yukarıda bahsedilmiş olan bu özellikler ve değerlendirilebilen verilere dayalı olarak, çalışmada seçim yanlılığını kontrol etmek için eğilim skoru eşleştirme yöntemi kullanılmıştır.

Eğilim Skoru Eşleştirme (Propensity Score Matching: PSM) Yöntemi

Eğilim skoru eşleştirme (PSM) yöntemi içerisinde, ortalama müdahale etkisi (average treatment effect: ATE) ve müdahale edilmiş grup üzerindeki ortalama müdahale etkisi (average 
treatment effect on the treated: ATET) belirlenmiştir.

\section{Ortalama Müdahale Etkisi ve Müdahale Edilmiş} Grup Üzerindeki Ortalama Müdahale Etkisi

Çalışmanın bu bölümünün amacı, yıllık toplam tarımsal gelir ve işletme varlıkları ekonomik büyüklüklerinin oluşturulması ve/veya geliştirilmesi davranışına yönelik, üreticilerin TDH'nden yararlanmasının ortalama müdahale etkisini (ATE) (average treatment effect:ATE) ve müdahale edilmiş grup üzerindeki ortalama müdahale etkisini (average treatment effect on the treated:ATET) tahmin etmektir. Ortalama müdahale etkisini tahmin etmek için ideal bir durum, aynı birim için iki çıktının karşılaştırılmasıdır. Bu iki birim de; müdahaleye maruz kalan ve kalmayan gruplardır (Imbens and Wooldridge, 2009). Çalışmanın bu bölümünde örneğin, üretici TDH'nden yararlandığı ya da yararlanmadığı zaman, tarımsal işletmelerde elde edilen yıllık toplam tarımsal gelir ve işletme varlıklarının ekonomik büyüklükleri karşılaştırılarak ortalama müdahale etkisi tahmin edilebilmektedir. Deneysel verilerin eksikliği durumunda, ATE'nin tahmin edilmesinin en büyük zorluğu, eğer üretici TDH'nden yararlanmamış olsaydı, yıllık toplam tarımsal gelir ve işletme varlıklarının ekonomik büyüklüğünün oluşturulması ve/veya geliştirilmesi davranışının ne olduğunun bilinmemesidir. Bu sebeple, gözlenemeyen karşıt durumun tesisi, ATE'nin değerlendirmesinin temel problemi olarak kalmaktadır (Ferraro and Pattanayak, 2006). Rosenbaum and Rubin (1983), gözlenemeyen karşıt durumu aşmak için, deneysel olmayan ortamlarda sıklıkla kullanılan PSM yaklaşımını geliştirmiştir. PSM, TDH'nden yararlanan herbir üretici ile benzer özelliklere sahip TDH'nden yararlanmayan üreticileri eşleştirme yolu ile istatiksel bir karşılaştırma grubu tesis eder. Esasında, PSM modeli, TDH'nden yararlanan ve yararlanmayanların tesadüfi olarak atandığı bir deney koşullarını oluşturarak, müdahale etkilerinin yansız bir tahminini sağlar ve $T D H^{\prime}$ nden yararlanma ve tarımsal işletmede yıllık toplam tarımsal gelir ve işletme varlıklarının ekonomik büyüklüğünün oluşturulması ve/veya geliştirilmesi davranışı arasında olağan bir bağlantıyı tanımlamak için kullanılmaktadır (Pan, 2014).

Rosenbaum ve Rubin (1983)'e göre, bir karşıt durum çerçevesinde, ATE $\left(\Delta_{i}\right)$ aşağıdaki gibi tanımlanabilmektedir:

$\Delta_{i}=Y_{i}^{1}-Y_{i}^{0}$

burada, $Y_{i}^{1}$ ve $Y_{i}^{0}$ sirasıyla, TDH'nden yararlanan $i$ üreticisi ile yararlanmayan $i$ üreticisinin yıllık toplam tarımsal gelir ve işletme varlıklarının ekonomik büyüklüğünün oluşturulması ve/veya geliştirilmesi davranışını ifade etmektedir. Denklem (5)'den i'nci üretici üzerinde TDH'nden yararlanmanın etkisinin tahmin edilmesi, kayıp veri probleminden dolayı yanıltıcı olabilmektedir. Normal olarak, zamanın belirli bir noktasında, bir üretici için ya $Y_{i}^{1}$ ya da $Y_{i}^{0}$ çıktısının birisi (her ikisi değil) gözlenebilmektedir. Normal olarak gözlenen veri aşağıdaki gibi açıklanabilmektedir:

$Y_{i}=D_{i} Y_{i}^{1}+\left(1-D_{i}\right) Y_{i}^{0}$

burada, $D, T D H^{\prime}$ nden yararlanmayı işaret eden bir kukla değişkendir. ATET, TDH'nden yararlanmış olan üreticilerin elde etmiş oldukları çıktılar ile yine TDH'nden yararlanmış olan üreticilerin, eğer bu destekten yararlanmamış olsalar idi, beklenen olası çıktılar arasındaki fark olarak tanımlanmaktadır. ATET, aşağıdaki gibi ifade edilebilmektedir (Smith and Todd, 2005):

$A T E T=E\left(Y_{i}^{1} \mid D_{i}=1\right)-E\left(Y_{i}^{0} \mid D_{i}=1\right)=E\left(Y_{i}^{1}-Y_{i}^{0} \mid D_{i}=1\right)$

$E\left(Y_{i}^{1} \mid D_{i}=1\right)$,e ait veri, TDH'nden yararlanan üreticilerden elde edilebilmektedir. Fakat $E\left(Y_{i}^{0} \mid D_{i}=1\right)$ 'e ait veri ise bir karşıt durum çıktısı olup, veri bir üretici tarafından gözlenememektedir. Bu sebeple, genellikle gözlenebilen ATE, aşağıdaki gibi açıklanabilmektedir: 
$A T E=E\left(Y_{i}^{1} \mid D_{i}=1\right)-E\left(Y_{i}^{0} \mid D_{i}=0\right)$

$A T E=\left[E\left(Y_{i}^{1} \mid D_{i}=1\right)-E\left(Y_{i}^{0} \mid D_{i}=1\right)\right]+\left[E\left(Y_{i}^{0} \mid D_{i}=1\right)-E\left(Y_{i}^{0} \mid D_{i}=0\right)\right]$

$A T E=A T E T+E\left(Y_{i}^{0} \mid D_{i}=1\right)-E\left(Y_{i}^{0} \mid D_{i}=0\right)$

Eğer, TDH'nden yararlanma, tesadüfi olarak belirleniyorsa, yararlanma kukla değişkeni $D$, istatiksel olarak çıktıdan bağımsızdır $\left(Y_{i}^{1}, Y_{i}^{0}\right)$ ve müdahale edilmemiş (TDH'nden yararlanmamış) bireylerin çıktı ortalaması olan $E\left(Y_{i}^{0} \mid D_{i}=0\right)$, $E\left(Y_{i}^{0} \mid D_{i}=1\right)$ için bir vekil (proxy) olarak kullanılabilmektedir. Ancak, deneysiz (nonexperimental) anket çalışmalarında, müdahale edilen ve edilmeyen gruplar, müdahaleyi almadan önce aynı olmayabilir. Bu sebeple, deneysiz çalışmalarda, bir müdahalenin etkisini analiz etmek için ATE kullanıldığı zaman, $E\left(Y_{i}^{0} D_{i}=1\right)-E\left(Y_{i}^{0} D_{i}=0\right) \quad$ seçim yanlılığının oluştuğunu işaret etmektedir. Bu sebeple, TDH için, veri bir yararlanmama durumunda, TDH'nin etkilerini tahmin etmek için Denklem (8)'in kullanımı, yanlı tahminciler üretebilmektedir (örneğin, seçim yanlılığından kaynaklanan). Etki analizinin asıl amacı, seçim yanlılığını sıfıra indirmek $\left(E\left(Y_{i}^{0} \mid D_{i}=1\right)-E\left(Y_{i}^{0} \mid D_{i}=0\right)=0\right)$ olup, öyle ki ATET=ATE olması için çözümler bulmaktadır. PSM modeli, bu seçim yanlılığı durumu için kullanılabilmektedir (Pan, 2014).

PSM yönteminin geçerliliği, iki koşula bağlı bulunmaktadır:

Karıştırmama (unconfoundedness) ve koşullu bağımsızlık (conditional independence assumption: $\mathrm{CIA}$ ) varsayımı ve (2) ortak destek varsayımı (assumption of common support: CSA). Koşullu bağımsızlık varsayımı, veri bir gözlenebilir $X$ ortak faktörler seti, ilgili $Y_{i}^{1}$ ve $Y_{i}^{0}$ müdahale çıktıları, $D$ gerçek TDH'nden yararlanma düzeyinden bağımsız olmaktadır. Bunun notasyonu aşağıda gösterilmiştir (Pan, 2014):

$\left(Y_{i}^{1}, Y_{i}^{0}\right) \perp P / X$

Dolayısıyla, gözlenebilir farklılıkların düzenlenmesinden sonra, potansiyel çıktı ortalaması, $\quad \mathrm{D}=1 \quad$ ve $\quad \mathrm{D}=0 \quad$ için,
$\left(E\left(Y_{i}^{0} \mid D_{i}=1\right)=E\left(Y_{i}^{0} \mid D_{i}=0\right)\right)$
aynıdır. Koşullu bağımsızlık varsayımı, TDH'nden yararlanmış olan üreticilerin, eğer bu desteklerden yararlanmamış olsalar idi, göstermiş oldukları performansı ölçmek için, TDH'nden yararlanmayan üreticilerin eşleştirilmiş olarak kullanımına izin vermektedir. Koşullu bağımsızlık varsayımı altında, bu çalışmanın içeriğindeki eğilim skoru, üreticilerin veri bir TDH'nden yararlanma öncesi durum özellikleri ile bir üreticinin $\mathrm{TDH}^{\prime}$ nden yararlanmasını ifade eden koşullu bir olasılığı tanımlamaktadır. Bu durum aşağıda ifade edilmiştir:

$p(X)=\operatorname{Pr}(D=1 \mid X)=E(D \mid X) ; p(X)=F\{h(X i\}$

burada, $F\{$.$\} normal ya da lojistik kümülatif$ dağılım olabilmekte ve $X$ müdahale (TDH'nden yararlanma) öncesi karakteristiklerin bir vektörünü ifade etmektedir.

Diğer taraftan, ortak destek varsayımı, herbir bireyin, bir TDH'nden yararlanıcı olma ya da olmama durumuna ilişkin pozitif bir olasılığa sahip olunmasını teminat altına alması ile tam öngörülebilirlik fenomenine imkan vermemektedir. Ortak destek varsayımı aşağıdaki gibi açıklanabilmektedir:

$0<\operatorname{Pr}(D=1 \mid X)<1$

Koşullu bağımsızlık varsayımı ve ortak destek varsayımı altında, ATET aşağıdaki gibi tahmin edilebilmektedir (Pan, 2014):

$$
\begin{aligned}
& \operatorname{ATET}=E\left(Y_{i}^{1} \mid D_{i}=1\right)-E\left(Y_{i}^{0} \mid D_{i}=1\right) \\
& \left.=E\left(\left(Y_{i}^{1}-Y_{i}^{0}\right) \mid D_{i}=1\right)\right) \\
& =E\left\{E\left[\left(Y_{i}^{1}-Y_{i}^{0}\right) \mid D_{i}=1, p(X)\right]\right\} \\
& =E\left\{E\left[Y_{i}^{1} \mid D_{i}=1, p(X)\right]-E\left[\left(Y_{i}^{0} \mid D_{i}=0, p(X)\right] D_{i}=1\right\}\right.
\end{aligned}
$$

\section{Araştırma Bulguları ve Tartışma}

Üreticilerin genel yaş ortalamasının 47.62 olduğu tespit edilmiştir. Ortalama eğitim seviyenin 7.58 yıl gibi yüksek bir düzeyde olduğu 
belirlenmiş olup, bu durum da göstermektedir ki artık, üreticilerin eğitim seviyelerinin yıllar itibarıyla daha da artacağına işaret etmektedir. Deneyim olarak; uzun yıllardır çiftçilik ile uğraştıkları ve bu tecrübelerini önemsedikleri, hem üretimlerinin şekillenmesinde, hem de üretim modellerinde yıllar içinde kazandıkları deneyimler ile karar aldıkları gözlenmiştir. Hane sayısı ortalaması 4.24 ve hanede tarımda çalışan kişi sayısı ortalaması 1.84 olarak hesaplanmıştır. Üretici gelirlerini, büyük oranda tarımsal üretimleri ile karşıladıkları ve aile iş gücünün büyük oranda üretime katılmakta olduğu belirlenmiştir (Çizelge3).

Çizelge 3. Üreticiler ile ilgili genel bilgiler ve özellikler

Table 3. General characteristics and features in relation with the producers

\begin{tabular}{|c|c|c|c|c|c|c|}
\hline $\begin{array}{l}\text { Genel bilgiler } \\
\text { General information }\end{array}$ & $\begin{array}{c}\text { Açıklama } \\
\text { Explanation }\end{array}$ & $\begin{array}{c}\text { Ortalama } \\
\text { Mean }\end{array}$ & $\begin{array}{l}\text { Standart } \\
\text { sapma } \\
\text { Standard } \\
\text { deviation }\end{array}$ & $\begin{array}{l}\text { Minimum } \\
\text { Minimum }\end{array}$ & $\begin{array}{l}\text { Maksimum } \\
\text { Maximum }\end{array}$ & $\begin{array}{l}\text { Medyan } \\
\text { Median }\end{array}$ \\
\hline $\begin{array}{l}\text { Yaş } \\
\text { Age }\end{array}$ & $\begin{array}{c}\text { yıl } \\
\text { year }\end{array}$ & 47.62 & 10.64 & 25.00 & 86.00 & 47.00 \\
\hline $\begin{array}{l}\text { Eğitim } \\
\text { Education }\end{array}$ & $\begin{array}{c}\text { yıl } \\
\text { year }\end{array}$ & 7.58 & 3.36 & 5.00 & 18.00 & 5.00 \\
\hline $\begin{array}{l}\text { Deneyim } \\
\text { Experience }\end{array}$ & $\begin{array}{l}\text { yıl } \\
\text { year }\end{array}$ & 22.18 & 11.09 & 2.00 & 60.00 & 20.00 \\
\hline $\begin{array}{l}\text { Hanedeki birey sayısı } \\
\text { The number of members in the } \\
\text { household }\end{array}$ & $\begin{array}{c}\text { adet } \\
\text { number }\end{array}$ & 4.24 & 1.60 & 1.00 & 8.00 & 4.00 \\
\hline $\begin{array}{l}\text { Hanedeki tarımda çalışan sayısı } \\
\text { The number of employees working } \\
\text { in agriculture in the household }\end{array}$ & $\begin{array}{c}\text { adet } \\
\text { number }\end{array}$ & 1.84 & 1.07 & 0.00 & 7.00 & 2.00 \\
\hline
\end{tabular}

Çizelge 4. TDH'nden yararlanma kararına yönelik kullanılan değişkenler

Table 4. Variables used intended for decision benefit of ACS

\begin{tabular}{|c|c|c|}
\hline $\begin{array}{l}\text { Değişkenler } \\
\text { Variables }\end{array}$ & Açıklama Explanation & Ortalama Mean \\
\hline \multicolumn{3}{|l|}{$\begin{array}{l}\text { Bağımlı değişken } \\
\text { Dependent variable }\end{array}$} \\
\hline $\begin{array}{l}\text { TDH'nden yararlanma } \\
\text { The benefit from ACS }\end{array}$ & $\begin{array}{c}\text { 1: evet } \\
\text { 1: yes } \\
0: \text { diğer durum } \\
0: \text { otherwise }\end{array}$ & 0.50 \\
\hline \multicolumn{3}{|l|}{$\begin{array}{l}\text { Bağımsız değişkenler } \\
\text { Independent variables }\end{array}$} \\
\hline $\begin{array}{l}\text { Yaş } \\
\text { Age }\end{array}$ & $\begin{array}{c}\text { yil } \\
\text { year }\end{array}$ & 47.62 \\
\hline $\begin{array}{l}\text { Eğitim } \\
\text { Education }\end{array}$ & $\begin{array}{c}\text { yıl } \\
\text { year }\end{array}$ & 7.58 \\
\hline $\begin{array}{l}\text { Çiftçilik deneyimi } \\
\text { Farming experience }\end{array}$ & $\begin{array}{c}\text { yıl } \\
\text { year }\end{array}$ & 22.18 \\
\hline $\begin{array}{l}\text { Hanede tarımda çalışan kişi sayısı } \\
\text { The number of employees working in agriculture in the household }\end{array}$ & $\begin{array}{c}\text { adet } \\
\text { number }\end{array}$ & 1.85 \\
\hline $\begin{array}{l}\text { Tarımsal kooperatife üyelik durumu } \\
\text { The situation of the member of an agricultural cooperative }\end{array}$ & $\begin{array}{c}\text { 1:evet } \\
1: \text { yes } \\
0: \text { diğer durum } \\
0: \text { otherwise }\end{array}$ & 0.46 \\
\hline $\begin{array}{l}\text { İşletme özelliği } \\
\text { Farm characteristic }\end{array}$ & $\begin{array}{l}\text { 1: karma işletme } \\
\text { 1: mixed farm } \\
0: \text { diğer durum } \\
0: \text { otherwise }\end{array}$ & 0.15 \\
\hline
\end{tabular}


Çizelge 5. Müdahale etkisinin belirlenmesine yönelik kullanılmış olan çıktı değişkenleri Table 5.Output variables used intended for defining of treatment effect

\begin{tabular}{|c|c|c|c|}
\hline $\begin{array}{l}\text { Değişkenler } \\
\text { Variables }\end{array}$ & $\begin{array}{l}\text { Açıklama } \\
\text { Explanation }\end{array}$ & $\begin{array}{l}\text { TDH'nden } \\
\text { yararlanan } \\
\text { işletmeler } \\
\text { The farms benefit } \\
\text { from ACS }\end{array}$ & $\begin{array}{c}\text { TDH'nden } \\
\text { yararlanmayan } \\
\text { işletmeler } \\
\text { The farms couldn't } \\
\text { benefit from ACS }\end{array}$ \\
\hline $\begin{array}{l}\text { Yıllık toplam tarımsal gelir } \\
\text { Annual total agricultural income }\end{array}$ & TL & $49,231.39$ & $34,598.59$ \\
\hline $\begin{array}{l}\text { İşletme varlıklarının toplam ekonomik } \\
\text { büyüklüğü } \\
\text { Total economic size of farm assets }\end{array}$ & $\begin{array}{l}1=10,000 \mathrm{TL} \text { ve altı } \\
2=10,001-50,000 \mathrm{TL} \\
3=50,001-100,000 \mathrm{TL} \\
4=100,001-500,000 \mathrm{TL} \\
5=500,001-1,000,000 \mathrm{TL} \\
6=1,000,000 \mathrm{TL} \text { üzeri }\end{array}$ & 4.15 & 3.37 \\
\hline
\end{tabular}

Çizelge 6. TDH'nden yararlanma durumuna ilişkin olarak eğilim skorlarının lojit regresyon modeli ile tahmini

Table 6. Specification of propensity scores using with logit regression model concerning to benefit from ACS

\begin{tabular}{|c|c|c|c|c|}
\hline $\begin{array}{l}\text { Değişken } \\
\text { Variable }\end{array}$ & $\begin{array}{l}\text { Katsayı } \\
\text { Coefficient }\end{array}$ & $\begin{array}{l}\text { Standart hata } \\
\text { Standard error }\end{array}$ & z & $\mathrm{p}$ \\
\hline $\begin{array}{l}\text { Yaş } \\
\text { Age }\end{array}$ & 1.009 & 0.028 & 0.32 & 0.746 \\
\hline $\begin{array}{l}\text { Eğitim } \\
\text { Education }\end{array}$ & 1.139 & 0.066 & 2.24 & $0.025^{*}$ \\
\hline $\begin{array}{l}\text { Çiftçilik deneyimi } \\
\text { Farming experience }\end{array}$ & 1.035 & 0.026 & 1.34 & 0.182 \\
\hline $\begin{array}{l}\text { Hanede tarımda çalışan kişi sayısı } \\
\text { The number of employees working in agriculture in the } \\
\text { household }\end{array}$ & 1.135 & 0.206 & 0.70 & 0.485 \\
\hline $\begin{array}{l}\text { Tarımsal kooperatife üyelik durumu } \\
\text { The situation of the member of an agricultural cooperative }\end{array}$ & 2.661 & 0.996 & 2.61 & $0.009 * *$ \\
\hline $\begin{array}{l}\text { İşletme özelliği } \\
\text { Farm characteristic }\end{array}$ & 3.265 & 1.857 & 2.08 & $0.038 *$ \\
\hline $\begin{array}{l}\text { Sabit } \\
\text { Intercept }\end{array}$ & 0.048 & 0.064 & -2.26 & $0.024^{*}$ \\
\hline \multicolumn{5}{|l|}{ Log likelihood $=-88.630 ;$ Pseudo $R^{2}=0.1058$} \\
\hline Prob $>$ chi2 $=0.0019 * * ;$ Gözlem sayısı $=143$ & & & & \\
\hline
\end{tabular}

**, * sırasıyla $p<0.01$ ve $p<0.05$ istatiksel önem düzeyini ifade etmektedir.

Çalışmanın bu bölümünde öncelikle bir ikili (binary) lojit model kullanılarak, TDH'nden yararlanma kararını etkileyen faktörler tahmin edilmiştir. Öncelikle modelde kullanılan değişkenlere ait özet istatistikler aşağıda sunulmuştur (Çizelge 4.).

İkili lojit model kullanılarak, TDH'nden yararlanma kararını etkileyen faktörler tahmin edilmiştir (Çizelge 5).

Ayrıca, TDH'nden yararlanmanın etkisinin belirlenmesine yönelik yapılan analizde çıktı olarak kullanılmış olan değişkenlere ait tanımlayıcı veriler de aşağıda sunulmuştur (Çizelge 6 ).

-88.630 olan Log likelihood değeri, tahmin edilen modelin istatiksel olarak \%1 düzeyinde $(p<0.01)$ önemli olduğunu ortaya koymaktadır. Pseudo- $R^{2}$ değeri de, denklemin, üreticilerin TDH'nden yararlanıp-yararlanmaması hakkındaki karar vermedeki değişimin \%10.58'ini açıkladığını ortaya koymaktadır. Sonuçlara göre; daha eğitimli, herhangi bir tarımsal kooperatife üye olan üreticiler ve karma işletme özelliği gösteren işletmelere sahip üreticilerin, TDH'nden daha yüksek yararlanma olasılı̆̆ına sahip oldukları belirlenmiştir. Hesaplanmış olan, TDH'nden yararlanmanın sağlamış olduğu etkilerin belirlenmesine yönelik ATE ve ATET değerleri aşağıda sunulmuştur ( Çizelge 7). 
Çizelge 7. TDH'nden yararlanmanın sağlamış olduğu ATE ve ATET değerleri Table 7. ATE and ATET values via benefited from ACS

\begin{tabular}{|c|c|c|c|c|c|c|}
\hline $\begin{array}{l}\text { Değişkenler } \\
\text { Variables }\end{array}$ & ATE & $\begin{array}{l}\text { Standart } \\
\text { hata } \\
\text { Standard } \\
\text { deviation }\end{array}$ & $\begin{array}{c}\text { \%95 düzeyinde güven } \\
\text { aralığı } \\
\text { 95\% confidence } \\
\text { interval }\end{array}$ & ATET & $\begin{array}{l}\text { Standart } \\
\text { hata } \\
\text { Standard } \\
\text { deviation }\end{array}$ & $\begin{array}{c}\text { \%95 düzeyinde güven } \\
\text { aralığı } \\
\text { 95\% confidence } \\
\text { interval }\end{array}$ \\
\hline $\begin{array}{l}\text { Yıllık toplam tarımsal } \\
\text { gelir } \\
\text { Annual } \\
\text { agricultural income }\end{array}$ & 4,986 & 8,859 & $-12,378-22,350$ & 4,972 & 12,906 & $-20,324-30,269$ \\
\hline $\begin{array}{l}\text { İşletme varlıklarının } \\
\text { ekonomik büyüklüğü } \\
\text { Total economic size of } \\
\text { farm assets }\end{array}$ & 0.44 & 0.20 & $0.41-0.84$ & 0.31 & 0.28 & $-0.24-0.85$ \\
\hline
\end{tabular}

Illk olarak ATE değerleri incelendiğinde; tüm üreticilerin $\mathrm{TDH}^{\prime}$ nden yararlanması durumunda, işletme başına düşen yıllık ortalama toplam tarımsal gelir, üreticilerin hiçbirinin TDH'nden yararlanmaması durumuna göre elde edilecek gelirden 4,986 TL daha fazla olacağı belirlenmiştir. Yine, tüm üreticilerin TDH'nden yararlanması durumunda, işletme varlıklarının ekonomik büyüklüğü, üreticilerin hiçbirinin $\mathrm{TDH}^{\prime}$ nden yararlanmaması durumunda oluşacak büyüklükten 0.44 kategori (derece) daha yüksek olacağı belirlenmiştir.

ATET sonuçları değerlendirildiğinde ise; TDH'nden yararlanan tüm üreticiler için, bu üreticilerin elde ettikleri yıllık toplam tarımsal gelir, bu üreticilerin (TDH'nden yararlanan) TDH'nden yararlanmaması durumunda elde edecekleri gelirden 4,972 TL daha fazla olduğu belirlenmiştir. Yine, TDH'nden yararlanan tüm üreticiler için, bu üreticilerin elde ettikleri işletme varlıklarının ekonomik büyüklüğü, bu üreticilerin, TDH'nden yararlanmaması durumunda elde edecekleri ekonomik büyüklükten 0.31 kategori daha fazla olmaktadır.

\section{Sonuçlar}

$\mathrm{Bu}$ çalışmada, Balıkesir ilinde, TDH'nden yararlanan ve yararlanmayan işletmeler, karşıt durum etki değerleme yöntemi kullanılarak analiz yapılmıştır. Yörede, gayeli olarak belirlenmiş olan 143 işletmeyle yüz yüze anket uygulaması gerçekleştirilmiştir. 72 işletme TDH'nden yararlanan, 71 işletme ise TDH'nden yararlanmayan işletmelerden seçilmiştir. Etki değerleme analizinde; TDH'nin, tarımsal işletmelerde elde edilen yıllık ortalama toplam tarımsal gelir ve işletme varlıklarının ekonomik büyüklüğü üzerine etkileri analiz edilmiştir. Bunun için, ortalama müdahale etkisi (Average Treatment Effect: ATE) değerleri incelendiğinde; tüm üreticilerin TDH'nden yararlanması durumunda, işletme başına düşen yıllık ortalama toplam tarımsal gelir, üreticilerin hiçbirinin TDH'nden yararlanmaması durumuna göre elde edilecek gelirden 4,986 TL daha fazla olacağı belirlenmiştir. TDH'nden (müdahaleden) yararlanmış işletmelerde, TDH'nin etkisini ortaya koyan (Average Treatment Effect on Treated: ATET) analiz sonuçları değerlendirildiğinde ise; TDH'nden yararlanan tüm üreticiler için, bu üreticilerin elde ettikleri yıllık toplam tarımsal gelir, bu üreticilerin (TDH'nden yararlanan) TDH'nden yararlanmaması durumunda elde edecekleri gelirden 4,972 TL daha fazla olacağı belirlenmiştir. Yine, ATE sonucuna göre; tüm üreticilerin TDH'nden yararlanması durumunda, işletme varlıklarının ekonomik büyüklüğü, üreticilerin hiçbirinin TDH'nden yararlanmaması durumunda oluşacak büyüklükten 0.44 kategori (derece) daha yüksek olacağı belirlenmiştir. ATET sonucuna göre ise, TDH'nden yararlanan tüm üreticiler için, bu üreticilerin elde ettikleri işletme varlıklarının ekonomik büyüklüğü, bu üreticilerin, TDH'nden yararlanmaması durumunda elde edecekleri ekonomik büyüklükten 0.31 kategori daha fazla olacağı belirlenmiştir.

Sonuç olarak, tarımsal danışmanlık hizmetlerinin desteklenmesinin, tarımsal gelir ve üreticilerin sahip oldukları ekonomik varlıklar 
üzerindeki etkisinin oldukça önemli olduğu belirlenmiştir. Söz konusu destekleme modelinin, dinamik olarak geliştirilerek sürdürülmesinin faydalı olacağı öngörülmektedir.

\section{Ekler}

Bu çalışma, Adnan Menderes Üniversitesi Fen Bilimleri Enstitüsü'nde, Hakan IMAMOĞLU tarafından tamamlanmış olan "Tarımsal Danışmanlık Hizmetinin Tarımsal Üretim Üzerine Etkilerinin Analizi: Balıkesir İli Örneği” isimli Yüksek Lisans Tezinin belirli bir bölümünden oluşturulmuştur.

\section{Kaynaklar}

Ali, A., Abdulai, A., 2010. The adoption of genetically modified cotton and poverty reduction in Pakistan. Journal of Agricultural Economics, 61 (1): 175-192.

Balcı, A., 2011. Sosyal Bilimlerde Araştırma Yöntem, Teknik ve Illkeler. Gözden Geçirilmiş ve Geliştirilmiş 9. Baskı. PEGEM Akademi, 101s.

Balıkesir GTHB İ Müdürlüğü, 2015. Balıkesir Gıda, Tarım ve Hayvancılık ì Müdürlüğü. Koordinasyon ve Tarımsal Veriler Şube Müdürlüğü verileri. https://balikesir.tarim.gov.tr/Menu/49/Koordinasyo n-Ve-Tarimsal-Veriler. Erişim tarihi: 14.10.2015.

Blackman, A., Naranjo, M.A., 2012. Does eco-certification have environmental benefits? Organic coffee in Costa Rica. Ecological Economics, 83: 58-66.

Çınar, G., 2009. Üreticilerin Tarımsal Yayım ve Danışmanlık Hizmetleri İçin Ödemeye İstekli Oldukları Ücretlerin Belirlenmesi: Aydın illi Örneği. Yüksek Lisans Tezi, Adnan Menderes Üniversitesi, Fen Bilimleri Enstitüsü, Aydın, 76s.

Çukur, T., 2007. Türkiye'de Uygulanan Tarımsal Yayım Politikaları ve AB'ye Uyum Açısından Öneriler Üzerine Bir Araştırma. Doktora Tezi, Ege Üniversitesi, Fen Bilimleri Enstitüsü, İzmir, 275s.

Dehejia, R.H., Wahba, S., 2002. Propensity score-matching methods for nonexperimental causal studies. The Review of Economics and Statistics, 84 (1): 151-161.

Ferraro, P.J., Pattanayak, S.K., 2006. Money for nothing? A call for empirical of program evaluation of biodiversity conservation investments. Plos Biology, 4 (4): 0482-0488.

Gitonga, Z.M., De Groote, H., Kassie, M., Tefera, T., 2013. Impact of metal silos on households' maize storage, storage losses and food security: An application of a propensity score matching. Food Policy, 43: 44-55.

GTHB, 2016. Gıda, Tarım ve Hayvancılık Bakanlığı, 2016 Yılı Faaliyet

Raporu.
http://www.tarim.gov.tr/SGB/Belgeler/Bakanl\%C4\% B1k_Faaliyet_Raporlar\%C4\%B1/2016\%20YILI\%20BAK ANLIK\%20FAAL\%C4\%BOYET\%20RAPORU.pdf. Erişim tarihi: 30.06.2017.

Heckman, J.J., Ichimura, H., Todd, P.E., 1997. Matching as an econometric evaluation estimator: Evidence from evaluating a job training programme. The Review of Economic Studies, 66 (4): 605-654.

Imbens, G.W., Wooldridge, J.M., 2009. Recent developments in the econometrics of program evaluation. Journal of Economic Literature, 47 (1): 586.

Kahramanoğlu, R., Tiryaki, E.N., Canpolat, M., 2015. İlkokula yeni başlayan 60-66 ay grubu öğrencilerin okula hazır oluşları üzerine inceleme. K.Ü. Kastamonu Eğitim Dergisi, 23(3): 1065-1080.

Kassie, M., Shiferaw, B., Muricho, G., 2011. Agricultural technology, crop income, and povery alleviation in Uganda. World Development, 39 (10): 1784-1795.

Kızılaslan, N., Erdemir, S, 2013. Tarım danışmanlarının tarımsal yayım ve danışmanlık sistemindeki rolleri ve sisteme bakış açıları (Tokat ili merkez ilçe araştırması). Gaziosmanpaşa Bilimsel Araştırma Dergisi, 6: 67-84

Monette, D.R., Sullivan, T.J., De Jong, C.R., 1990. Applied Social Research: Tool for the Human Services. 2nd ed. London: Harcout Brace Jovanovich College Publishers.

Özen, Y., Gül, A., 2007. Sosyal ve Eğitim Bilimleri Araştırmalarında Evren-Örneklem Sorunu. Atatürk Üniversitesi Kazım Karabekir Eğitim Fakültesi Dergisi, 15: 394-422.

Pan, D., 2014. The impact of agricultural extension on farmer nutrient management behavior in Chinese rice production: a household-level analysis. Sustainability, 6: 6644-6665.

Rosenbaum, P.R., Rubin, D.B., 1983. The central role of the propensity score in observational studies for causal effects. Biometrica, 70, 41-55.

Smith, J.A., Todd, P.E., 2005. Does matching overcome Lalonde's critique of nonexperimental estimators? Journal of Econometrics, 125(1-2): 305-353.

Şimşek, H., Yıldırım, A., 2013. Sosyal Bilimlerde Nitel Araştırma Yöntemleri. 9. Baskı, Seçkin Yayıncılık, Ankara. 135s.

TCRG, 2016. Tarımsal Yayım ve Danışmanlık HizmetlerineDestekleme Ödemesi Yapılması Hakkında Tebliğ. Tebliği No: 2016/25. 10 Ekim 2016 tarih, 29853 sayılı Türkiye Cumhuriyeti Resmi Gazetesi.

Tunalıoğlu, R., Çınar, G., 2013. Aydın Ilinde Kamu Alanında Görev Yapan Tarımsal Yayım Personelinin Performanslarının Incelenmesi. Süleyman Demirel Üniversitesi Ziraat Fakültesi Dergisi, 8 (2): 11-22.

Yavuz, O., 2000. Tarımsal Yayım ve Haberleşme. Uludağ Üniversitesi, Ziraat Fakültesi Tarım Ekonomisi Bölümü, Bursa, 143s. 